\title{
The Impact of Emerging Market Trends on the Development and Marketing of Financial Service Products in Zimbabwe Post Dollarization
}

\author{
Tinevimbo Chokuda ${ }^{1}$, Wilford Mawanza², Farai Chimboza ${ }^{2}$ \\ ${ }_{1}^{1}$ Midlands State University, Gweru, Zimbabwe \\ ${ }^{2}$ Lupane State University, Bulawayo, Zimbabwe \\ chokudatv@gmail.com,wilfordma@gmail.com,faraichimboza@gmail.com
}

\begin{abstract}
The research sought to analyse the impact of emerging market trends as measured by competition, technology and consumer demographics on the development and marketing of financial service products in Zimbabwe post dollarization. The Zimbabwean financial service sector has been largely characterised by new and changing market trends since dollarization. These trends have largely manifested in the form of entrance of new players in the market, a growing informal sector at the expense of the formal financial sector and the emergence of new technology paving way for the need to develop and market new financial service products. There is therefore need for financial service providers in Zimbabwe to continually embrace innovative product development and marketing strategies so as to shape banking products to fit consumers' evolving financial needs much of which are well beyond the realm of traditional banking products. An explanatory research design was adopted in conjunction with a descriptive research design. Results from the study indicate that the entry of new financial institutions, removal of barriers between institutions, emergence of non-regulated financial institutions, increased consumer access to financial information owing to increased adoption of technology, market fragmentation and increased formal unemployment have a significant impact on the way financial service products are structured, provisioned. In light of that, it is recommended that financial service providers should design and tailor new business models to suit the emerging market environment.
\end{abstract}

\section{Keywords: Emerging market trends, development, financial services, Zimbabwe, post-dollarization}

\section{Introduction}

According to Gundani (2015) the financial services sector remains the bedrock for economic development by virtue of it being a conduit for economic transactions. This sector has seen significant structural transformation over the years, which has forced change in the marketing, design and delivery of financial service products. Globally, the financial services industry has been subjected to new and changing market trends which have forced significant and revolutionary changes to the shape of the financial landscape. The liberalization of the Zimbabwean financial sector through the Economic Structural Adjustment Program (ESAP) in 1990 saw a shift from a state interventionist to a more market driven financial system. This created new opportunities for entrance of new players into the financial services sector and gave rise to the emergence of new business classes notably microfinance institutions which came as a response to the need for provision of micro credit by Small to Medium Enterprises and the informal sector which had been largely ignored by the formal financial sector. More recently, an additional banking class of deposit taking microfinance institutions (Microfinance Banks) has since been issued with licences by the central bank (Mangudya, 2015a). Prior to liberalisation, the Zimbabwe financial sector followed a largely oligopolistic banking structure marred by a few expatriate banks such as Barclays and Standard Bank which continue to dominate the market until today. This was a heavily segmented structure which confined categories of financial institutions to specific types of business (Moyo, 2008). Building societies were only limited to real estate and mortgage financing, commercial banks were limited to the provision of short term working capital finance and merchant banks were responsible for wholesale and long term financing.

According to Nhavira, Mudzonga and Mugocha (2014), the deregulation of the financial services sector and emergence of new financial instruments and service offerings has blurred the boundaries between different types of financial institutions such as banking, insurance and securities and previous delineations which prohibited banks to underwrite insurance policies (banc assurance) or engage in other forms of non-banking activities have since been lifted. Also, various acts of legislation have been modified to allow for the convergence of previously separated segments of the financial services sector. The Banking Act was amended in 2000, allowing financial institutions to transform into commercial banks by acquiring additional functions 
on their licences (Nhavira, Mudzonga and Mugocha, 2014). There has been a notable increase in microfinance activities by conventional banks as they are permitted under the Microfinance Act (Chapter 24:29) to engage in microfinance business and lending activities (Mangudya, 2015b). Mobile Network Operators such as Econet (EcoCash), NetCash, Telecel (TeleCash) and Net One (One wallet) have ventured into the provision of financial service products and in the process have changed the nature of competition in Zimbabwe. Banks and other non-banking financial institutions are regulated by the Reserve Bank of Zimbabwe while these telecommunication companies are regulated by the Post and Telecommunication Regulatory Authority of Zimbabwe (POTRAZ). They are thus able to successfully compete on the same products in the same market with banks and other financial institutions taking advantage of regulation differences while at the same time circumventing RBZ regulations on financial service provision.

In addition, the emergence of mobile money and more recently mobile banking following the advent of increased use of information and communication technology for providing and availing financial services has changed the face of financial service provision in Zimbabwe. After dollarization in 2009, there was increased adoption and acceptance of technology by financial institutions and the general public. This has led to the crafting of alternatives to traditional banking models and the elimination of branch banking through telebanking (call centres'), internet banking, ATMs and mobile banking to avail financial services, provide investment advice as well as financial information. According to Mangudya (2015a), there has been a significant increase in the use of electronic payment methods as well as growth in the number of electronic access points and devices by financial institutions in Zimbabwe particularly the mobile money payment platforms. This has encouraged both product and geographical diversification and enabled financial institutions to provide new service offerings as well as standardise and harmonise the internal processes for new service delivery mechanisms.

Furthermore, demographic developments have been largely responsible for the gradual change in the desired asset liability structure of household portfolios (Freedman and Goodlet, 1998). These developments include a growing informal sector in Zimbabwe with an increasing fraction of the active labour force being absorbed into the informal sector leading to low levels of income and wealth. Henceforth, financial service providers are forced to shift from offering credit products such as personal loans to providing wealth management products such as mutual funds and mortgage financing which has been a noticeable trend in the Zimbabwe financial services industry. According to the Zimbabwe Economic Policy Analysis and Research Unit (ZEPARU) and the Bankers Association of Zimbabwe (BAZ) (2014), the Zimbabwean economy is undergoing significant structural transformation with the formal sector being progressively replaced by a growing informal sector which implies that traditional business models cannot continue to be applied hence the need to proffer new business models to serve the new emerging class of business clientele. In light of such a background, this research seeks to assess the impact of these emerging market trends on the development and marketing of financial services in Zimbabwe.

Problem Statement: The Zimbabwean financial service sector has been largely characterised by new and changing market trends since dollarization. These include the entrance of new players in the market, growing informal sector at the expense of the formal financial sector and the emergence of new technology paving way for the need to develop and market new financial service products. Therefore, there is need for financial service providers in Zimbabwe to continually embrace innovative product development and marketing strategies so as to shape banking products to fit consumers evolving financial needs (much of which are well beyond the realm of traditional banking products). It is therefore the purpose of this study to assess the impact of these emerging trends on the development and marketing of financial services in Zimbabwe and how financial institutions are adapting to these changes in financial service delivery.

Objectives of the Study: The study primarily seeks to assess the impact of emerging market trends on the development and marketing of financial services in Zimbabwe post dollarization. The sub-objectives of the study are:

- To identify the emerging market trends affecting financial service development and marketing in Zimbabwe.

- To investigate these individual trends are affecting financial product development and marketing in Zimbabwe. 
- To analyse the impact of these trends on the way financial services are structured, provisioned and delivered.

- To assess how these changes have affected the uptake of financial services in Zimbabwe.

\section{Literature Review}

According to Gundani (2015), the financial services sector remains the bedrock for economic development in Zimbabwe. The financial services sector plays a predominant role in stimulating and sustaining economic growth (Anand and Murugaiah, 2004 and Sutton and Jenkins, 2007). This shows the virtual importance of the increasing need to develop and market financial products and services by financial service providers in Zimbabwe. The focus of any marketing activity should be on the consumer and customer satisfaction is central to successful marketing. According to Farquhar and Meidan (2010) the argument for customer centric marketing is irrefutable due to emerging market trends notably increasing market diversity, intensifying competition, accelerating advances in technology as well as demanding and well informed customers. These trends reinforce the need for financial service providers to transform from product-customer centricity to customer centric marketing of financial services. According to Harrison and Estelami (2014), financial institutions and academics alike are increasingly acknowledging the need for new perspectives and paradigms in financial services marketing. According to Alao et al. (2014) banks and financial institutions now compete on a new competitive platform where marketing philosophy and practice have become a strong means of staying ahead of the game. According to Harrison and Estelami (2014), the public's limited ability to fully comprehend financial offers, complexity of financial decisions, unobservable product features and the extent of limited consumer education on financial decision making have presented a challenge for financial service marketers in the marketing of financial offers. In turn, this has further intensified the need for effective financial service marketing in the financial services sector.

Also, according to Farquhar and Meidan (2010) the array of financial products has noticeably expanded with increased provision of some highly unconventional financial services such as life settlement contracts which have further intensified competition and the need for optimisation of marketing capabilities in financial service organisations. Conversely, Harrison and Estelami (2014) assert that the need for a paradigm shift in financial services marketing is enhanced by the low levels of public confidence in both the financial institutions and the financial system as a whole. This has also been supported by Estelami (2012) who asserted that lack of consumer trust and confidence in the financial service providers is an inherent characteristic of many financial service transactions and securing a sense of mutual trust between financial institutions and consumers presents a challenge for financial services marketers. Alao, Diyaolu and Afuape (2014) also concur that the issue of public trust and confidence in the financial system calls for possible changes to the marketing paradigm in the financial services sector.

Unique Aspects of Financial Services Marketing: According to Estelami (2012), financial services marketing is a unique and highly specialised branch of marketing which makes selling, advertising, pricing and distribution of financial service products far more complex than that of consumer goods. It should be of note that before financial service providers can successfully device strategies for effective marketing of financial services, there is need to appreciate the distinctions between marketing of financial services and marketing of consumer or industrial goods. Jan (2012) also concurs that services are different from tangible consumer goods and hence require different marketing frameworks and identified Heterogeneity, Inseparability, Intangibility and Perish- ability as the specific characteristics which make services marketing a unique specialisation. Swankie and Watson (2006) also identified four fundamental differences between marketing of financial services and marketing of consumer goods that is Fiduciary Responsibility, Intangibility, Inseparability and Lack of Standardisation (Heterogeneity).

Developments in the Financial Services Sector: According to Freedman and Goodlet (1998), the rapid pace of these changes has left financial service providers struggling to determine the appropriate strategic direction for future development and marketing of financial services. According to La Croix et al (2002), in considering the current and future trends that are likely to have a significant bearing on the shape of the financial services industry, two (2) criteria are important: 
- Relevance that is identification of trends that actually have a bearing on the revolution of the financial landscape.

- Predictability and permanence that is identification of trends which have a high probability to continue having significant bearing on the financial services sector.

This entails that financial service providers in Zimbabwe have to be in a position to identify the key predictable market trends relevant to the Zimbabwean financial sector and its operating environment.

In a slightly different analogy, Grais and Kantur (2003) proposed that there are three (3) driving forces to change that is financial liberalisation, technological developments and market innovation in response to demand for financial services. In addition however, these driving forces induce four major trends in the financial landscape that is disintermediation, institutionalisation, modernisation and globalisation. According to Grais and Kantur (2003), the driving forces have led to profound changes in the financial services sector and contributed to its ability to offer more diverse products. In turn these trends have affected the driving forces influencing liberalisation and institutional reforms as well as the adaptation of new technologies thereby inducing further creativity on the part of financial institutions. This notion has also been supported by La Croix et al. (2002) suggesting that there exists a relationship between emerging trends and the three major forces.

Emerging Market Trends: Owing to liberalization and deregulation reforms in the financial services sector, the previous boundaries between different types of financial institutions are being blurred (Freedman and Goodlet, 1998; Ekerete, 2005; Joseph, 1997). According to Joseph (1997), liberalisation facilitated by technological innovation has led to increased competition in the financial services sector spawning new financial instruments, new financial institutions and the blurring of barriers between different classes of financial institutions. Highlighting the distinguishing features between financial institutions, Ekerete (2005) argued that all financial institutions offer complementary rather than competing products but however the distinctions are more theoretical rather than practical and there seems to be a narrowing down or removal of the line of demarcation between them. Estelami (2012) adds that the financial landscape is becoming highly competitive making the marketing of financial services a highly unique discipline. Deregulatory measures have allowed financial service providers to cross product market boundaries which had partitioned the market for decades. This has contributed to the increased industry concentration, consolidation and mergers between and among financial service providers and market power is being concentrated in many financial service categories hence the need for focused and well calculated marketing strategies to ensure long term success and optimisation of marketing capabilities (Estelami, 2012).

The financial services sector has in recent years been challenged by the emergence of new competitors from both within and outside of the financial services sector. Estelami (2012) asserts that there has been a significant shift in the type of competitors that traditional financial service providers have to compete with today as insurance companies, telecommunication companies through mobile money which were primarily providers of predefined financial products are now encroaching the boundaries and can provide products related to investment, time deposits, retirement planning and other services traditionally provided by banking and investment institutions. In concurrence, Joseph (1997) asserts that increased competition has been spread fairly rapidly within the banking sector and between banks and non-bank financial institutions. Consequently, due to this intensified competition, financial institutions have been subjected under increasing pressure to embrace financial innovation especially in terms of new business models, a new range of products and institutions resulting from the merging of business among various financial institutions (most notably banking and insurance) to offer a new range of financial services (banc assurance).

Technology: The process and technologies for providing financial services is undergoing revolutionary change Estelami (2012). This recent technology boom has created a digital age which has had a significant impact on the ways in which financial services are structured, provisioned and delivered to the customer (Kotler and Armstrong, 2012). According to Freedman and Goodlet (1998), the most important factor propelling change in the financial services sector has been technological developments especially those in information processing, management and financial services delivery. In addition, increased adoption of Information and Communication Technology in the financial sector has dramatically increased access to the service offerings and financial information and this has had a profound impact on the financial services sector 
and the old adage of traditional branch banking has been slowly replaced by the extended or 24 hour availability of financial services (La Croix et al., 2002). According to Farquhar and Meidan (2010), the growing use of technology in the delivery of financial services has led to growing customer confidence in the consumption of technology based financial service products and has promoted the globalisation of financial services. This has in turn led to a shift in the balance of power between financial service providers and consumers as customers gain confidence both in understanding financial offers and realising that the competitive environment provides extensive choice.

Consumer Demographics: According to Once (2000), changes in the population structure and composition affect the quality and attributes of consumers as the beneficiaries of banking services and products. In a different light, Freedman and Goodlet (1998) argue that changing consumer demands have not been an important factor in driving changes in the financial services sector but rather consumers have adjusted their behaviour in response to innovations in financial services and instruments initiated by financial service providers. Also, according to Alao, Diyaolu and Afuope (2014), the issue of market fragmentation has greatly influenced the dynamism of the competitive landscape and customer base of individual banks. Estelami (2012) adds that there is mounting evidence that financial service markets are challenged by a highly fragmented consumer base characterised by high consumer debt, rising bankruptcy rates, demographic shifts and diverse income owing to increased formal unemployment hence financial services designed to serve these consumers may need to become more diverse in order to keep up with the market's increased fragmentation. Henceforth, banks and other financial institutions have to grapple with different issues of market fragmentation which include demographic shift, social status shift, population shift, loyalty shift among others, to design more tailor made financial services that keep up with increasing degree of market fragmentation and consumer sophistication.

\section{Methodology}

The study primarily adopted a descriptive research design as this research seeks to draw new insights on the impact of emerging market trends, determined by the changing nature of competition, technological advancements and changing customer demographics, on financial service marketing in Zimbabwe. The research focused on four (4) main categories of financial institutions in Zimbabwe that is banking institutions, insurance companies, asset management firms and microfinance institutions. The focus was on eighteen (18) operational banking institutions and one hundred and forty seven (147) microfinance institutions in Zimbabwe. The population also comprised (15) asset management firms, twenty seven (27) registered short term insurance companies in Zimbabwe.

Sampling Design: The research sample comprised of managers of financial institutions and marketing personnel. Stratified random sampling was adopted for the research in order to cover the scope of financial service provision in Zimbabwe and ensure better representation of the whole population. In that regard, the target population was divided into four (4) strata as follows:

Table 1: Total Sample Size

\begin{tabular}{ll}
\hline Financial Institutions Category & Number of Respondents \\
\hline Banking Institutions & 10 \\
Insurance Companies & 10 \\
Microfinance Institutions & 10 \\
Asset Management firms & 5 \\
Total & 35 \\
\hline
\end{tabular}

Source: Raw Data

Data Types and Sources: Self-administered questionnaires and personal interviews were used to collect primary data from the management and marketing personnel of financial institutions. Primary data enabled the collection of up to date data directly from the experts in the field which was relevant to the specific requirements of the research thereby enhancing the objectivity of the research. However, primary data collection demanded a lot of input from the researcher in terms of questionnaire distribution, conducting interviews as well as obtaining feedback from the respondents. Secondary data was obtained largely through 
desk research and the researcher consulted a diverse range of data sources which included online publications, journals as well as Reserve Bank of Zimbabwe (RBZ) reports and publications. These sources provided a detailed insight into the subject matter under study and aided in providing vital information for designing the questionnaires for the research. The use of secondary data enabled comparisons and analysis of past trends which aided the researcher in the interpretation of collected data. However, it was a daunting task to filter relevant information from the large volumes of data as some of the detail failed to meet the exact requirements of the research. Also, there was no control over the procedure for collecting, analysing and interpreting the data which compromised the objectivity and accuracy of the data.

Model Specification: The research adopted the Spearman Rank Correlation Coefficient to analyse the impact of emerging market trends as measured by Competition, Technology and Consumer Demographics on the marketing of financial services as measured by the key marketing mix elements (Product, Price, Promotion and Place). The model was selected on the basis of its ability to measure the degree of association (correlation) between two sets of variables that is competition, technology and consumer demographics on one hand and product, price, promotion and place on the other. In addition, the Spearman Rank Correlation Coefficient uses ranked data to determine the degree of association or correlation between two sets of variables hence an appropriate choice for the study considering the nature and type of data required for the research. The model made use of primary data collected through the self-administered questionnaires. In line with previous studies carried out by Ekerete (2005) and more recently by Alao, Diyaolu and Afuope (2014), the model adopted by the researcher is represented by the following formula:

$\begin{array}{lll}\text { Where } & r= & \text { Correlation Coefficient (Spearman rho) } \\ d= & \text { Difference between ranked values } \\ d^{2}= & \text { Square of the difference } \\ & \sum d^{2}= & \text { Total of squared differences } \\ n= & \text { Number of paired variables or observations }\end{array}$

$$
r=1-\frac{6 \sum d^{2}}{n\left(n^{2}-1\right)}
$$

The critical value (t) (representing $r$ at 0.05 confidence level) is used to test the significance of the $r$ value. The researcher used Stata 12 to estimate the parameters of the model in respect to reliability and multicollenearity. Necessary measures were taken to address irregularities in the model variables. Error tests involved the elimination of outliers and omitted variables (resulting from data entry errors by the researcher) which could have caused misleading inferences and distorted the findings of the research.

\section{Results and Discussion}

The research started by looking at Emerging Market Trends and their Impact on the Uptake of Financial Services in Zimbabwe and the following is the discussion of each.

Changing Nature of Competition: Respondents were requested to highlight the extent to which the changing nature of competition has affected the uptake of financial service products in Zimbabwe in relation to increased competition between financial institutions, removal of barriers to entry in the industry, entry of non-regulated financial institutions, increased consolidation between financial institutions as well as the blurring of boundaries or demarcations between financial institutions. Arguments by Freedman and Goodlet (1998) where they stated that the rapid pace of changes in the market was creating a situation where financial service providers were struggling to determine the appropriate strategic direction for future development and marketing of financial services have proven to be an interesting precursor in light of the current study's findings. The findings of the study show how in varying degrees such factors as the changing nature of competition, increased competition between financial institutions, removal of barriers to entry in the industry, entry of non-regulated financial institutions, increased consolidation between financial institutions as well as the blurring of boundaries or demarcations between financial institutions have reconfigured the way financial service products are developed and marketed.

The findings of the research indicate that the removal of boundaries between financial institutions has affected to a great extent affected the uptake of financial services in Zimbabwe as indicated by a high mean of 4.59 and a low standard deviation of 0.74 which is indicative of the high significance of the impact as banks 
can now offer insurance, microfinance and investment products while microfinance banks can now offer microfinance services and accept deposits from customers. These results concur with Estelami (2012) who asserted that there has been a significant shift in the type of competitors that traditional financial service providers have to compete with today as insurance companies, telecommunication companies through mobile money which were primarily providers of predefined financial products are now encroaching the boundaries and can provide products related to investment, time deposits, retirement planning and other services traditionally provided by banking and investment institutions. The majority of the respondents also concur that increased competition between financial institutions, the entry of new financial institutions and increased consolidation between financial institutions particularly banks and insurance companies to provide an integrated service have affected to a considerable extent the uptake of financial service products in Zimbabwe. This is supported in literature by La Croix et al. (2002) who highlighted that the opportunity for choice delivered by new entrants has generally increased the power of the consumers evidenced by growing resistance to the product and service fee structures, decreasing loyalty to primary providers as well as acceptance of new traditional brands and propositions.

In addition, the entry of non-regulated financial institutions such as Ecocash, Telecash and One Wallet have also had a significant impact on the uptake of financial services in Zimbabwe. However, the significance of the impact is relatively lower than the other factors relating to the changing competitive landscape as indicated by a higher standard deviation of 0.9885 and a lower mean of 3.85 as shown in table 4.10 below. These results are in line with Levin (2013) who postulated that non-regulated financial institutions in particular mobile money service providers have been able to alter the financial landscape and have become a dominant payment system in Zimbabwe by moving beyond offering peer to peer money transfer services to become a multifunctional payment platform which has been able to compete effectively with banks and other financial institutions in the financial sector. Also, according to Mbiti and Weil (2011) the explosive growth in mobile money mirrored by the number of agents and service locations has changed the competitive landscape in the financial services sector and has enabled it to compete with and replace modalities such as cheques and other traditional payment systems. This highlights the significance of the impact of non-regulated financial service providers on the financial landscape and how they have altered the extent of service provision as well as the nature of competition in the financial services sector.

Table 2: Impact of Competition on the Uptake of Financial Service Products

\begin{tabular}{lcclcc}
\hline Variable & Obs & Mean & Std. Dev. & Min & Max \\
\hline Increased competition & 27 & 4.222222 & .8006408 & 2 & 5 \\
New FIs & 27 & 4.074074 & .8738036 & 2 & 5 \\
Non-regulated FIs & 27 & 3.851852 & .9885383 & 2 & 5 \\
Industry consolidation & 27 & 4.074074 & .957799 & 2 & 5 \\
Boundaries & 27 & 4.592593 & .7472647 & 2 & 5 \\
\hline Source: Stata 12 & & & & &
\end{tabular}

Source: Stata 12

Technological Innovations: The study also sought to establish the extent to which technology has affected the uptake of financial service products in Zimbabwe in relation to increased consumer access to information on services provided by competitors as well as how technological innovations such as internet banking, mobile banking and elimination of branch banking through the use of ATMs have affected the uptake of financial service products by consumers. Table 3 below summarises the findings

Table 3: Impact of Technological Innovations on the Uptake of Financial Service Products

\begin{tabular}{lccccc}
\hline \multicolumn{1}{c}{ Variable } & Obs & Mean & Std. Dev. & Min & Max \\
\hline Innovations & 27 & 4.592593 & .5723944 & 3 & 5 \\
Information access & 27 & 4.37037 & .564879 & 3 & 5 \\
\hline
\end{tabular}

Source: Stata 12

Table 3 above shows that technological innovations and increased access to information on financial services provided by customers have to a great extent affected the uptake of financial service products in Zimbabwe. In the same vein, Ekerete (2005) who suggested that the influence of modern technology on marketing of 
financial services has revolutionised bank services delivery and that there is a significant positive relationship between modern information technology adoption and effective marketing strategy.

Also, the increased adoption of technology by financial institutions has increased consumer access to financial service products as well as to information on financial services provided by other financial institutions in the industry. Farquhar and Meidan (2010) also share the same view that there is a shift in the balance of power between financial institutions and consumers as customers gain confidence in the adoption of technology based financial services as well as understanding financial services and realising that the competitive environment provides extensive choice. In concurrence, Harrison and Estelami (2014) propounded that the ease of access helps enhance the ability of the consumers to tap into critical information for efficient financial decision making thereby increasing the power of the consumers to choose between service offerings and the financial service providers.

Changing Consumer Demographics: The study also set to investigate how changing consumer demographics in relation to increasing unemployment (growing informal sector), market fragmentation (increasing gap between the rich and the poor) as well as consumer trust and confidence in the financial institutions have affected the uptake of financial service products in Zimbabwe.

Table 4: Impact of Changing Consumer Demographics on the Uptake of Financial Service Products

\begin{tabular}{llllcc}
\hline \multicolumn{1}{c}{ Variable } & Obs & Mean & Std. Dev. & Min & Max \\
\hline Unemployment & 27 & 4.407407 & 1.118352 & 1 & 5 \\
Market fragmentation & 27 & 3.962963 & 1.159625 & 2 & 5 \\
Trust and Confidence & 27 & 4.814815 & .4833407 & 3 & 5 \\
\hline
\end{tabular}

Source: Stata 12

Research findings indicate that consumer trust and confidence in the financial institution has a significant impact on customer perception about the services provided by the institution as signified by a low standard deviation of 0.483 and hence significantly affects the uptake of financial service products. These results are in line with Estelami (2012) who stated that securing a sense of mutual trust between financial institutions and consumers remains a continuing challenge to the practice of financial services marketing as lack of consumer trust and confidence is an inherent characteristic of many financial service transactions. In addition, market fragmentation has to a considerable extent affected financial services marketing and the uptake of financial services in Zimbabwe as signified by a lower mean of 3.96 and a higher standard deviation of 1.16. However, the significance of this impact cannot be undermined as this has had a profound influence on the way financial service product are structured and provided. This coincides with Alao, Diyaolu and Afuope (2014) who highlighted that the issue of market fragmentation has greatly influenced the dynamism of the competitive landscape and customer base of individual banks. Estelami (2012) also adds that financial services designed to serve these consumers may need to become more diverse in order to keep up with the market's increased fragmentation.

Also, the majority of respondents agreed that increased unemployment and growth of the informal sector has to a great extent affected the structure and nature of financial service products provided by financial institutions and has significantly affected the uptake of financial services in Zimbabwe. According to ZEPARU and BAZ (2014), the Zimbabwean economy has undergone significant structural transformation in the past decade that has inevitably propelled the growth of informal sector with an increasing number of the active labour force being absorbed in the informal sector. Hence, the growing trend in formal unemployment calls for financial service providers to develop new financial services and proffer new marketing mechanisms that are best able to serve this emerging class of business clientele. These findings are line to those of once (2000) that highlighted that changes in the population structure and composition affect the quality and attributes of consumers as the beneficiaries of banking services and products.

Impact of Emerging Market Trends on the Marketing of Financial Services: The research adopted the Spearman Rank Correlation Coefficient to determine the relationship between emerging market trends and marketing of financial services in line with previous studies by Ekerete (2005) and Alao, Diyaolu and Afuope (2014). This two variable regression model used the rankings of the explanatory variables that is product, 
price, promotion and place (MFS) on one arm and competition, technology and consumer demographics (EMT) on the other as determined by twenty seven (27) financial institutions in Zimbabwe (see Appendix).

\section{Testing of the Hypothesis}

$\mathrm{HO}=$ There is no significant correlation between emerging market trends and marketing of financial services. $\mathrm{H} 1=$ There is a significant relationship between emerging market trends and marketing of financial services.

Decision Rule: The spearman rho $(r)$ assumes value from -1 indicating negative correlation to +1 indicating positive correlation between the explanatory variables. If the spearman rho is greater or equal to $r$ at $n=27$ ( 0.05 confidence level) reject the null hypothesis and accept the alternative hypothesis. On the other hand, if the $r$ value is less than the critical value $(\mathrm{t})$, accept the null hypothesis (Alao, Diyaolu and Afuape, 2014).

\section{Computation of the Spearman Rank Correlation Coefficient}

Figure 1: Spearman Rank Correlation Coefficient

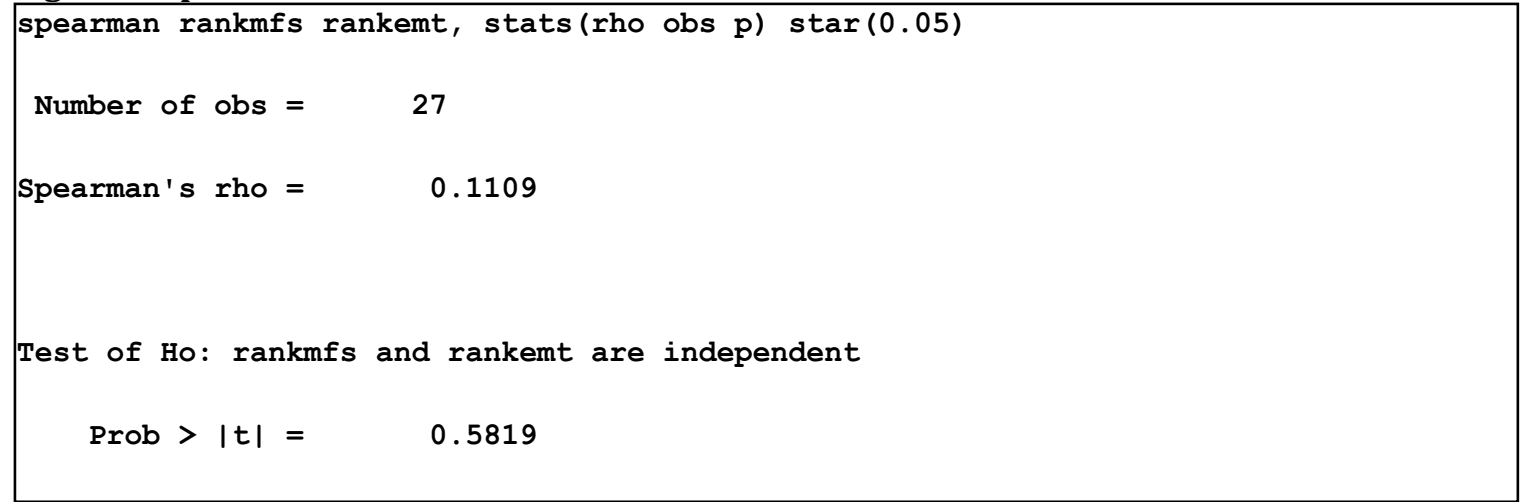

Source: Stata 12

Figure 4.2 above shows the computation of the Spearman Rank Correlation Coefficient in Stata 12. The $r$ value of 0.1109 implies a weak positive correlation between emerging market trends as measured by competition, technology as well as consumer demographics and marketing of financial services measures in terms of the extent to which financial institutions in Zimbabwe apply the marketing mix variables in their marketing effort. However, since the $r$ value of 0.1109 is less than the critical $(t)$ value of 0.5819 the null hypothesis is accepted that is there is no significant correlation between marketing of financial services and emerging market trends. Although a weak correlation exists between these explanatory variables, the significant impact of competition, technology and consumer demographics on financial services marketing cannot be undermined.

\section{Conclusion and Recommendations}

In light of the above, the following conclusions can be drawn from the study:

- The research concludes that new service development is important for the success of the organisation. However, it should be centred on the needs of the customers as financial institutions in Zimbabwe serve a diverse range of customers which include civil servants, corporate, SMEs and the largely increasing informal sector. Hence financial products aimed at serving this diverse clientele may need to be customised or tailor made to suit the needs of each individual customer for successful marketing of financial services.

- The research also concludes that the era of armchair banking in the Zimbabwe financial services sector is over. Increased competition and increased consumer access to financial information on products provided by competitors have led to shifting demand for services and financial products on the part of retail customers. There is constant need for financial institutions to promote financial service offerings through sales promotions, personal selling and direct marketing as well as to promote consumer awareness of products provided by the financial institutions through providing organisational material such as pamphlets and brochures. 
- There has been dramatically increased access to offerings of the industry and information about these offerings through technological innovation particularly internet banking, mobile banking, mobile money and increased adoption of technology based financial service products by consumers. This has led to a balance of power between financial service providers and consumers as consumers have greater autonomy to choose between financial service offerings and financial service providers. This has been enhanced by consumers growing resistance to traditional brands and decreasing loyalty to primary service providers as well as acceptance of new financial propositions (mobile money).

- Also, the study concludes that non-regulated financial institutions such as EcoCash, One Wallet, NetCash and TeleCash have made inroads into the Zimbabwe financial services sector and have reduced the market share that traditional banks hold.

- Though conjecture and varying literature imply that there is a significant relationship between marketing of financial services and emerging marketing trends in terms of competition, technology and consumer demographics results from the study indicate that a weak relationship or correlation exists. Research results indicate that there are other factors which affect development and marketing of financial service products in Zimbabwe such as availability of funds, cost of operations, types of customers served by the institution, profitability of the organisation, types of services provided and size of the institution. Therefore, this entails that marketing of financial services may not be necessarily a function of competition, technology and consumer demographics as other factors may have a direct impact on the extent to which financial services are developed and marketed which may not necessarily be related to these emerging market trends.

Recommendations: In light of the above conclusions, the following recommends were put forward;

- Financial service providers should design and tailor new business models to suit the emerging market environment and emerging class of business clientele.

- The entrance of new players in the market, the growing informal sector at the expense of the formal financial sector and the emergence of new technology have paved way for the need to develop and market new financial service products. Therefore, financial service providers should continually embrace innovative strategies so as to shape banking products to fit consumers changing financial needs.

- Consolidation and merging of financial institutions to provide complementary service products for example microfinance and insurance companies can consolidate to sell short term insurance to the informal sector, individuals, SMEs which remain locked out of the formal financial system. This can also be adopted as an effective measure to tap into the resources circulating outside the financial system and bring the informal sector under the ambit of the formal financial system.

\section{References}

Alao, A. E., Diyaolu, G. O. \& Afuape, A. M. (2014). The changing trend in marketing of financial services: an empirical study on bank performance in Nigeria. International Journal of Business and Economic Development (IJBED), 2(2).

Anand, S. \& Murugaiah, V. (2004). Marketing of Financial Service: strategic issues.

Ekerete, P. P. (2005). Marketing of Financial Services: A Case Study of Selected Merchant Banks in Nigeria. Pakistan Economic and Social Review, 3, 271-287.

Estelami, H. (2012). Marketing financial services. 2nd Edition, Dog Ear Publishing.

Farquhar, J. D. \& Meidan, A. (2010). Marketing Financial Services. $2^{\text {nd }}$ ed. England: Palgrave MacMillan.

Freedman, C. \& Goodlet, C. (1998). The financial services sector: past changes and future prospects (No. 82). Bank of Canada.

Grais, W. \& Kantur, Z. (2003). The changing financial landscape: opportunities and challenges for the Middle East and North Africa. World Bank Policy Research Working Paper, (3050).

Gundani, K. (2015). Unpacking Banking Sector Challenges. The Zimbabwean Independent. Available at www.theindependent.co.zw. Accessed on 13 August 2015.

Harrison, T. \& Estelami, H. (2014) Paradigm Shift in Financial Services Marketing. The European financial review. Available at www.europeanfinancialreview.com. 
Jan, A. (2012). Services Marketing Theory Revisited: An Empirical Investigation into Financial Services Marketing. Journal of Business and Management, 4(4), 36-45. Available at www.iosrjournals.org. Accessed on 13 August 2015.

Joseph, A. (1997). Strategic Alliances in the Financial Services Sector: Implications for Trinidad and Tobago. Social and Economic Studies, 46(2/3), 199-229.

Kotler, P. \& Armstrong, G. (2012). Principles of Marketing. $4^{\text {th }}$ Ed. New Jersey: Prentice Hall.

La Croix, K., Stone, M. \& Komolafe, F. (2002). Managing change in the financial services industry. Journal of Change Management, 3(1), 81-95. Available at www.tandfonline.com.

Levin, P. (2013). Big Ambition Meets Effective Execution. How Eco Cash is Altering the Zimbabwe Financial Landscape. Accessed on www.gsma.com. Accessed 18 September 2015.

Mangudya, J. P. (2015a). Mid-Term Monetary Policy Statement: Beyond Stabilisation. Reserve Bank of Zimbabwe. Available at www.rbz.co.zw. Accessed 15 August 2015.

Mangudya, J. P. (2015b). Monetary Policy Statement: Rebalancing the Economy through Competitiveness and Compliance. Reserve Bank of Zimbabwe. Available at www.rbz.co.zw. Accessed 23 July 2015.

Mbiti, I. \& Weil, D. N. (2011)Mobile banking: The impact of M-Pesa in Kenya (No. w17129). National Bureau of Economic Research. Available at www.econstor.eu. Accessed 23 August 2015.

Moyo, T. (2008). Financial Sector Liberalization and the Poor: A Critical Appraisal. For the SAPRI - Zimbabwe Initiative Poverty Reduction Forum.

Nhavira, J. D. G., Mudzonga, E. \& Mugocha, E. (2014). Financial Regulation and Supervision in Zimbabwe: An Evaluation of Adequacy and Options. Available at www.elibrary.acbfpact.org. Accessed on 26 August 2015.

Once, G. (2000). Services Marketing in the Banking Sector and Recent Perceptions in Marketing Thoughts. Available at www.opf.slu.cz. Accessed on 01 September 2015.

Sutton, C. N. \& Jenkins, B. (2007). The Role of the Financial Services Sector in Expanding Economic Opportunity. Harvard University. Available www.havard.edu. Accessed on 27 August 2015.

Swankie, A. G. \& Watson, C. (2006). Marketing Financial Services. Book 1. $4^{\text {th }}$ Ed. The Chartered Institute of Bankers in Scotland. Available at www.charteredbanker.com. Accessed on 27 August 2015.

Zimbabwe Economic Policy Analysis and Research Unit (ZEPARU) and Bankers Association of Zimbabwe (BAZ). (2014). Harnessing Resources from the Informal Sector for Economic Development. Available at www.baz.org.zw. Accessed on 12 August 2015. 